\title{
PROSES RITUAL SÊBLANG OLEHSARI
}

\section{Oleh : Ammy Aulia Renata Anny}

(Pembimbing Tugas Akhir Dr. Bambang Pudjasworo, M.Hum dan Dr. Hersapandi, SST, MS.) Jurusan Seni Tari, Fakultas Seni Pertunjukan Institut Seni Indonesia Yogyakarta

J1. Parangtritis km 6,5, Sewon, Bantul, Yogyakarta email: auliacweetz@gmail.com (085745028697)

\begin{abstract}
ABSTRAK
Sêblang Olehsari adalah ritual adat yang ada di desa Olehsari, Banyuwangi Jawa Timur. Secara etimologi kata Sêblang berasal dari bahasa Osing yang merupakan akronim dari kata sêbêlé ilang yang artinya membuang sial. Ritual Sêblang Olehsari diselenggarakan setelah hari raya Idul Fitri dan dilaksanakan selama tujuh hari berturut-turut. Pada hari ketujuh dilakukan prosesi Idêr Bumi (berjalan mengelilingi desa Olehsari) dan keesokan harinya diadakan upacara Ngêlungsur atau siraman. Bagian terpenting dalam ritual ini adalah ketika penari yang terpilih berdasarkan garis keturunan, mampu menari selama tiga jam dalam kondisi kesurupan. Tertarik dengan melihat perubahan moral dan kognitif subjek, maka penelitian ini difokuskan untuk mengamati proses ritual yang dialami subjek ritual. Berdasarkan pada teori proses ritual Victor Turner yakni separasi, liminalitas, reagregasi, dan dalam ritual Sêblang Olehsari ini subjek juga mengalami tahap transformasi. Diharapkan hasil penelitian yang dikaji dengan perspektif Etnokoreologi ini, memberikan kontribusi pengetahuan yang lebih luas tentang ritual Sêblang Olehsari.
\end{abstract}

Kata kunci: Proses Ritual, Sêblang, Separasi, Liminalitas, Transformasi, dan Reagregasi.

\begin{abstract}
Sêblang Olehsari was customary ritual that existed in Olehsari village, Banyuwangi East Java. Etimologycally, Sêblang derived from Osing languages, acronyim from 'sêbêlé ilang' which mean unfortunate throw way. Sêblang Olehsari ritual held after the day of Eid Fitri during seven consecutive days. On the seventh days be a procession Idêr Bumi (walk around in the Olehsari village) and the next day held Ngêlungsur or steady ceremonial. The most important part in this ritual was when the dancer who elected based on line descent, and able to dancing during three hours in trance condition. Interest with moral and cognitive changes from subject, so this research focused to observe ritual process that subjects experienced. Based on ritual process theories of Victor Turner even separation, liminality, reagregation, and in this Seblang rituals subject also suffered transformation phases. Expected the results of research which is examined by ethnocoreological perspective, can contribute knowledge that was more widespread about Sêblang Olehsari ritual.
\end{abstract}

Keywords: Ritual Process, Sêblang, Separation, Liminality, Transformation and Reagregation.

\section{A. Pendahuluan}

Sêblang merupakan sebuah ritual sacral yang diperkirakan muncul pertama kali di daerah Bakungan sekitar tahun 1770-an.
(Heru SP Saputra, 2014: 2) Lagu serta gerakan tarinya, secara simbolis menceritakan tentang peristiwa yang pernah dicatat oleh Pigeaud maupun John Scholte, untuk mengawali persiapan perang para prajurit perempuan 
Blambangan selalu mengawalinya dengan upacara ritual Sêblang. (Hasnan Singodimajan, 2009: 2) Lain halnya dengan Sêblang di Olehsari yang dicatat oleh asisten wedono Glagah muncul ketika tahun 1930an, terjadi pandemik menjalar di desa Olehsari. (Hasnan Singodimajan, 2009: 1) Dipimpin oleh Saridin sebagai pawang yang mendapat wangsit untuk mengadakan ritual Sêblang secara besarbesaran.Ritual Sêblang Olehsari dilaksanakan sekitar pukul 14.00, hingga pukul 17.30 WIB. Penari sebagai mediator dalam ritual Sêblang Olehsari adalah seorang wanita muda, sedangkan mediator ritual Sêblang Bakungan adalah wanita yang sudah memasuki masa menopause. Kesamaannya adalah, kedua mediator tersebut menari dalam keadaan kesurupan atau trance selama ritual berlangsung. Upacara penyembahan atau penghormatan di mana tubuh penari berfungsi sebagai wadah atau medium, disebut sejenis tarian shamanisme. (Y. Sumandiyo Hadi, 2007: 100) Penentuan tanggal pelaksanaan dalam ritual Sêblang Olehsari juga harus melewati proses kêjiman terlebih dahulu, namun penyelenggaraan ritualnya harus jatuh pada hari Senin ataupun Jumat. (Wawancara dengan Sri Handayani, 2015)

Tari ritual ini dilakukan oleh penari dalam keadaan trance dan mempunyai beberapa motif gerak yang terdiri dari motif sapon, ndhaplang, égol, dan cèlèng mogok. (Wawancara dengan Sri Handayani, 2015) Motif-motif gerak ini dilakukan oleh penari tanpa adanya proses berlatih terlebih dahulu. Selama ini telah banyak penelitian yang mengulas ritual Sêblang dari berbagai perspektif, baik dari segi tata urutan ritualnya, makna dan fungsinya, estetikanya, serta analisis terhadap gerak tarinya. Ada hal yang belum secara detail diamati, yakni proses ritual yang dialami oleh penari Sêblang sebagai subjek ritual utama dalam upacara itu. Penari Sêblang disebut sebagai subjek utama dalam ritual, didasarkan pada persepsi umum masyarakat bahwa ketika penari berhasil „ndadie maka diyakini bahwa ritual ini telah diterima oleh para leluhurnya. Sehingga muncul beberapa rumusan masalah untuk mengetahui dan menjawab fenomena tersebut, mengenai bagaimana struktur teks tari Sêblang Olehsari dan proses ritual yang dialami penari Sêblang Olehsari?.

Pendekatan yang digunakan dalam penelitian ini adalah Etnokoreologi, karna dianggap sesuai sebagai kerangka pemikiran dengan asumsi, model, konsep, metode penelitian, metode analisis serta hasil hasil analisis untuk menjelaskan dan menafsirkan tari sebagai gejala kebudayaan di Nusantara. Objek materialnya adalah tari ritual Sêblang dan penari Sêblang sebagai subjek ritual, sedangkan objek formalnya adalah analisis proses ritual berdasarkan teori Victor Turner. Digunakan pula perspektif ilmu psikologi guna menjelaskan tentang fenomena trance dalam ritual Sêblang Olehsari.

\section{B. Pelaku Ritual Sêblang Olehsari}

Selain penari beberapa pendukung ritual Sêblang Olehsari diantaranya adalah: Pawang yang bertanggung jawab sebagai pemimpin dalam ritual, bertugas untuk menghadirkan dan mengembalikan roh dalam tubuh penari. Pengudang adalah dua atau tiga orang pria yang bertugas menemani penari bersama pendamping penari yakni seorang wanita lansia. Para pemain gamelan adalah lelaki dari desa setempat, dan sinden wanita yang berjumlah sekitar 5-6 orang.

\section{Prosesi Ritual Sêblang Olehsari}

Setiap upacara ritual selalu memiliki prosesi, yakni tahap-tahap yang harus dipersiapkan menjelang pelaksanaan suatu ritual begitupula dengan ritual. Setelah melakukan ziarah makam biasanya akan terjadi kêjiman pada salah satu warga, untuk memilih penari dan menetapkan waktu pelaksanaan. Rapat desa pun dilakukan guna membentuk kepanitiaan dan penanggung jawab dana, serta koordinasi untuk mempersiapkan Gênjot (tempat pertunjukan). Seseorang yang mengalami kêjiman bersama 
orang tua gadis yang terpilih menjadi mediator Sêblang, pada malam hari sebelum pelaksanaan menggelar acara selametan agar ritual berjalan lancar. Dalam ritual Sêblang juga disiapkan adanya sesaji sendiri yang terdiri dari tiga jenis berdasarkan kegunaan dan tempat peletakannya yakni sajén Buangan, Cawisan dan Para Bungkil.

Omprok merupakan aksesori yang dikenakan di kepala seorang penari Sêblang atau bisa juga disebut kuluke sêblang, terbuat dari bunga dan dedaunan segar. Dirangkai pada pagi hari sebelum Sêblang dilaksanakan seorang wanita lansia ketururnan para pembuat Omprok yang sebelumnya, dan dipercaya mampu menjadi perantara berkah. Acara selanjutnya adalah pementasan Sêblang Olehsari, diawali dari prosesi arak-arakan menuju tempat pementasan. Ritual Sêblang dimulai sekitar pukul 14.00- 17.30, berlangsung selama enam hari dan pada hari ketujur digelar prosesi Idêr Bumi. Prosesi Ngêlungsur atau siraman bagi para pendukung ritual dilakukan untuk megakhiri serangkaian acara ritual Sêblang Olehsari.

\section{Analisis Teks Tari Sêblang Olehsari}

Kajian tekstual artinya fenomena tari dipandang sebagai bentuk secara fisik (teks) yang relatif berdiri sendiri, yang dapat dibaca, ditelaah atau dianalisis secara tekstual atau men-teks" sesuai dengan konsep pemahamannya. Semata mata tari merupakan bentuk atau struktur yang nampak secara empirik dari luarnya saja atau surface structure, tidak harus mengkaitkan dengan struktur dalamnya (deep structure). (Y. Sumandiyo Hadi 2007: 23)

\section{Analisis Bentuk Gerak}

Prinsip bentuk yang dianalisis meliputi: kesatuan, variasi, repetisi atau ulangan, transisi atau perpindahan, rangkaian, perbandingan dan klimaks. (Y. Sumandiyo Hadi, 2003: 7284) Kesatuan berarti menjadi satu yang utuh, di mana gerak, ruang dan waktu menyatu dan memberi daya hidup pada bentuk gerak. Setiap motif gerakan yang dilakukan penari Sêblang selalu sesuai dengan hitungan lagu. Contohnya motif sapon yang terdiri darigerak kanan lalu kiri dalam empat hitungan, dalam lagu Sêblang Lukinto yang terdiri dari 2x8 hitungan

Variasi dalam gerak dipahami sebagai prinsip bentuk yang harus ada dalam suatu tarian, sebagai karya kreatif harus memahami yang serba „baru“e. Motif gerak dalam tari ritual ini variasinya terbatas pada gerak yang simetris, apabila diawali dari tubuh bagian kanan kemudian dilakukan sebaliknya pada tubuh bagian kiri.

Repetisi atau pengulangan, tanpa adanya aspek ini maka tangkapan inderawi penonton akan suatu gerakan akan cepat hilang begitu saja. Motif gerak yang dilakukan banyak sekali dilakukan repetisi, contohnya pada motif égol ukel buwang. Gerakan yang dilakukan penari selalu dilakukan berulangulang terdiri dari gerak ukel ke dalam lalu gerak buwang keluar.

Perpindahan atau transisi, aspek transisi memberikan tenaga hidup dari gerak sebelumnya dan berfungsi sebagai pengenalan pindah ke bentuk gerak berikutnya, sehingga bentuk kesatuan itu nampak utuh dan mengesankan. (Y. Sumandiyo Hadi, 2007: 27) Ketika irama alon penari melakukan gerak sêblak sampur 3x8 hitungan, ketika memasuki irama rambatan penari melakukan gerakan transisi yakni lémbéhan sampur $1 \times 8$. Saat memasuki irama rangkep penari melakukan gerakan égol ukel buwang tersebut $3 \times 8$, kemudian gerak transisi lagi.

Rangkaian dapat dianalisis sebagai sebuah kontinyuitas, yang perlu diperhatikan agar bentuk gerak dapat dirasakan sebagai suatu pengalaman. Sususnan motif gerak inti dalam tari ritual ini secara garis besar terdiri dari: motif sapon pada bagian awal, lalu memasuki bagian tengah saat lagu Cèlèng Mogok, penari melakukan motif gerak cèlèng mogok. Melakukan motif gerak ndhaplang ketika lagu Condro Dewi yang menandai tarian memasuki bagian akhir. Motif gerak sêblak sampur dan égol ukel buwang merupakan motif dominan atau motif gerak 
„isian“ yang sering dilakukan penari, selain ketiga motif inti tersebut.

Klimaks sangat berkaitan dengan penempatan suatu rangkaian gerak, yang telah dibahas sebelumnya. Dalam ritual Sêblang terdapat fase klimaks kerucut berganda, karna terdapat beberapa klimaks kecil sebelum mencapai puncak klimaks ketika lagu Condro Dewi.

\section{Analisis Tehnik Gerak}

Didalamnya terdapat beberapa jenis tehnik yang hendaknya dikuasai oleh penari yakni ,tehnik bentuk ${ }^{e e}$, „tehnik medium ${ }^{\text {ee }}$ dan „tehnik instrumen "e. Tehnik medium yang dimaksudkan adalah gerak, yang merupakan elemen dasar ekspresi dalam tari. (Y. Sumandiyo Hadi, 2007: 29) Tehnik instrumen adalah tubuh penari tersebut, yang dipahami sebagai intrumen yang digunakan ketika bergerak. Bagian-bagian tubuh yang dianalisis meliputi sikap badan, sikap tumpuan kaki, pandangan atau arah hadap dan sikap kepala.

a. Sikap gerak berdasarkan bagian anggota tubuh:

\section{Kaki}

Langkah loro tinjak, yakni gerak kaki pada motif sapon dan égol ukel buwang, langkah nyiji kerep dan langkah nyiji arang.

\section{Tangan}

Sapon $(\mathrm{kn} / \mathrm{kr})$, ndhaplang, cèlèng mogok, égol ukel buwang, sêblak sampur dan lémbéhan sampur.

\section{Kepala}

Gerak: deleg dhuwur kerep dan deleg dhuwur arang, ulat atau arah pandangan dalam tarian ini lebih cenderung ke arah bawah dan ke depan, dengan mata yang terus tertutup rapat selama menari.

\section{Badan}

Tulang belikat terlihat lebih mengarah ke depan, tidak seperti posisi tegap pada umumnya.

\section{b. Uraian motif Gerak:}

\section{Motif gerak sapon}

Motif gerak sapon atau bisa disamakan artinya dengan menyapu, dilakukan pada bagian awal saat penari sudah mulai trance saat lagu Sêblang Lukinto. Gerak ini menjadi suatu simbol cerminan bagi manusia untuk dapat membersihkan (menyapu) diri, dari segala macam jenis kotoran (sifat buruk) yang mendiami sikap dan perilaku manusia. (Lintang Habsari, 2012: 85)

\section{Motif gerak cèlèng mogok}

Lagu Cèlèng mogok menceritakan tentang tingkah laku seekor babi hutan, yang sedang bermalas-malasan. Lagu ini dilantunkan ketika penari juga melakukan motif gerakan cèlèng mogok. Makna dari motif gerak cèlèng mogok ini adalah menyiratkan simbol peringatan bagi masyarakat agar tidak malas-malasan, semangat dan bekerja keras untuk mempertahankan hidup. (Eko Wahyuni, 2009: 104)

\section{Motif gerak ndhaplang}

Motif gerak ini memiliki makna sebuah keseimbangan antara kelakuan baik dan buruk, keseimbangan kebutuhan jasmani dan rohani serta seimbang antara hal-hal yang merusak dengan hal yang membangun. (Lintang Habsari, 2012: 87) Motif gerak ini dilakukan pada saat lagu Condro Dewi dilantunkan, yang menandai bahwa telah memasuki bagian akhir tarian.

\section{Motif gerak égol}

Seperti yang telah dibahas pada beberapa literatur yakni buku berjudul Koreografi Etnik Jawa Timur oleh Eko Wahyuni Rahayu, dan sebuah skripsi berjudul Etnografi ritual Sêblang Olehsari yang ditulis oleh saudari Lintang Habsari dari Universitas Indonesia, 
menyatakan bahwa salah satu dari empat motif gerak dalam tari ritual Sêblang adalah égol. Kenyataannnya égol tidak pernah berdiri sendiri sebagai suatu motif gerak, sehingga lebih sesuai jika disebut sebagai unsur gerak. Ada motif gerak yang dominan yakni motif gerak sêblak sampur dan égol ukel buwang, pada motif inilah sebenarnya unsur gerak égol tersebut terlihat.

\section{Analisis Gaya}

Sêblang Olehsari merupakan gaya emblemik yang menjadi identitas desa Olehsari, sebab baik dari segi prosesi maupun proses ritualnya berbeda dengan ritual Sêblang yang ada di Bakungan. Dalam hal ini dipahami bahwa cakupannya meliputi sikap serta bentuk gerak, tata rias dan busana, syair lagu dan instrumen pengiringnya, alat yang digunakan dan sebagainya. Selain itu disebutkan dalam beberapa literature sejarah bahwa gerak tari yang dilakukan penari Sêblang, diyakini menjadi cikal bakal munculnya gerak tari-tari baru yang ada di Banyuwangi. Apabila diamati dari salah sikap gerak ketika motif ndhaplang, apabila ditambah aksi memperlebar volume diangkat ke atas maka akan menjadi sikap miwir sampur yang menjadi sikap khas dalam tari Banyuwangi. Tehnik penggunaan jarik dibuat mengecil pada bagian bawah, inilah yang menyebabkan eksplorasi gerak level bawah tidak banyak ditemui dalam tari tradisional Banyuwangi.

Bentuk gending dalam musik gaya Banyuwangi hampir serupa dengan bentuk lancaran di Jawa, namun letak bunyi kempul yang berada dihitungan genap, 2 dan 6 ketika irama alon dan hitungan 2, 4, dan 6 ketika irama rangkep. Laras selendro yang ada di Banyuwangi nadanya slereng atau hampir seperti laras pelog, karna disesuaikan dengan nada lagu serta vokal bahasa Osing yang dilantunkan. Ada hubungan khas yang khusus pada gerak dan iringan dalam tari banyuwangi, yakni sebagian besar gerakan diakhiri sebelum jatuh gong. Istilah ini dalam musik Banyuwangi disebut dengan mapag, di mana gerakan selanjutnya dimulai bersamaan bunyi gong. Contohnya dapat dilihat ketika penari melakukan motif gerak égol ukel buwang.

\section{Analisis Jumlah Penari}

Bentuk koreografi yang terdiri dari satu penari saja, biasa disebut dengan istilah solo dance. Menurut Sumandiyo Hadi, tarian yang dilakukan tunggal analisis tekstualnya dianggap lebih sederhana, harus memiliki kualitas, menguasai teknik, kreativitas berimprovisasi, percaya diri dan stamina yang prima, karena ia akan tampil secara tunggal di atas pentas dan menjadi pusat perhatian.

Tentunya beberapa kriteria tersebut juga sesuai bagi penari tunggal ritual Sêblang, terutama pada kedua poin terakhir yakni rasa percaya diri dan juga stamina, karena penari Sêblang menarikannya selama kurang lebih 3 jam dalam keadaan tidak sadarkan diri, mata terpejam dan berjalan mengitari arena berulang kali.

\section{Analisis Jenis Kelamin dan Postur Tubuh}

Tari ritual ini bukanlah jenis koreografi literal atau memiliki cerita, sehingga tidak memiliki kriteria khusus dalam menentukan postur tubuhnya. Hal yang terpenting untuk menjadi mediator dalam ritual Sêblang adalah seorang wanita muda, dan tentunya keturunan langsung dari penari sebelumnya. Penari Sêblang selalu berjenis kelamin perempuan, dengan postur tubuh yang tidak terlalu tinggi, kurus dan berkulit sawo matang. Sejauh ini beberapa aspek tersebut masih berlaku, setidaknya beberapa tahun terakhir para penari Sêblang memiliki ciri tersebut. Dengan postur demikian gerakan yang ditimbulkan tekesan lebih ringan, dengan kesan jangkauan volume gerak yang luas.

\section{Analisis Struktur Ruangan}

Desain ruang yang ditimbulkan merupakan wujud jangkauan penari dalam bergerak, menguasai arena pentasnya di atas Gênjot. 
Ruang imajiner yang dibentuk oleh penari adalah desain dari setiap gerak yang dilakukannya, sembari berputar mengelilingi Payung Agung sebagai porosnya. Terlihat adanya keterkaitan yang ditimbulkan, meski tidak terjadi kontak secara langsung. Tentunya ditambah dengan titik pandang segenap penonton dari segala arah yang menuju pada satu fokus, yakni penari Sêblang.

Arah lurus dan lengkung dianggap sebagai pola desain lantai yang paling awal dalam tari. Begitupula dengan penari Sêblang yang selalu melakukan geraknya dengan arah melengkung, karena hal ini dipengaruhi oleh bentuk panggung yang berbentuk lingkaran. Selain itu pola melingkar dalam suatu upacara ritual, merupakan wujud sebuah penyatuan yang mampu menciptakan sebuah magis proteksi atau perlindungan. Setiap gerakan yang dilakukan penari, dilakukan berlawanan dengan arah jarum jam atau berputar ke arah kiri mengitari Payung Agung sebagai pusatnya. Teknik berputar mengkirikan atau ke arah Utara disebut dengan Daksina. (Sumber: KBBI diakses pada 20-6-15) Istilah-istilah tersebut merupakan istilah penghormatan yang dikenal dalam ajaran agama Hindu dan Budha. Berputar ke arah melawan jarum jam serta menentang arus, hal ini merupakan perwujudan sebuah refleksi diri umat manusia. (Wawancara bapak Kardi Laksono, 2015)

\section{Analisis Struktur Dramatik}

Ritual Sêblang Olehsari ini lebih cenderung memiliki dinamika kerucut ganda, sebab sebelum mencapai puncak klimaks terdapat beberapa klimaks kecil terlebih dulu. Digambarkan bahwa pada bagian awal saat proses pemanggilan roh diiringi lagu Sêblang Lukinto, setelah penari trance kemudian melakukan motif gerak sapon. Selanjutnya terdapat bagian di mana para pelaku ritual selain penari, akan menjajakan bunga Dirma kepada penonton. Disusul adegan Tundhikan, di mana penari Sêblang menari bersama para penonton, kemudian pada fase pra klimaks utama terdapat lagu Cèlèng mogok. Motif gerak ndhaplang pada lagu Condro Dewi menjadi fase puncak klimaksnya.

\section{Analisis Tata Tehnik Pentas}

Bentuk lingkaran itu mengandung nilai kepercayaan, bahwa tuntunan yang disampaikan oleh Sêblang merupakan bagian dari kearifan untuk bergotong royong dan arah hadapnya ke Timur ,witan atau kawitan"e, mengandung makna awal dari suatu kehidupan baik dari arah maupun kekuatannya. (Hasnan Singodimajan, 2009: 41) Pementasan Sêblang Olehsari menggunakan arena berbentuk lingkaran, yang dinamakan Gênjot. Bagian belakang sebelah Barat dan menghadap ke arah Timur, terdapat bilik bambu yang digunakan untuk menggantung sesaji dan tempat para pesinden disebut Para Bungkil. Atap Para Bungkil dibuat dengan model gedang selirang, di mana bagian depan dibuat lebih tinggi dan bagian belakangnya lebih rendah. Bagian tengah arena terdapat Payung Agung yang merupakan sebuah simbol perlindungan, berwarna putih dan berukuran besar. Area dibawahnya digunakan untuk para pengrawit yang duduk melingkari, sedangkan tempat yang digunakan untuk menari mengitari area di luar Payung Agung sampai batas pagar arena. Area bawah di sekitar panggung merupakan tempat para penonton, sebab yang diperkenankan untuk naik ke atas panggung hanyalah para pendukung ritual serta pihak keluarga dan kerabat saja.

\section{Analisis Struktur Gerak}

Berdasarkan hasil analisis struktur pada gerak dalam tari Sêblang Olehsari, hubungan yang terjadi merupakan hubungan sintagmatis. Pada bagian awal tarian diiringi lagu Sêblang Lukinto penari melakukan motif gerak sapon. Ketika lagu Liliro Kantun dilantunkan, penari melakukan gerakan seblak sampur ketika irama alon dan gerak égol ukel buwang ketika irama rangkep. Setiap satu kali putaran lagu selalu menggunakan irama alon dan rangkep, kemudian diulang kembali hingga 3-4 kali. 
Gerakan ini terus dilakukan sesuai dengan urutan lagu selanjutnya, dan urutan lagu ini sudah terstruktur dan tidak dapat dipertukarkan. Ketika memasuki lagu Cèlèng Mogok, penari juga melakukan motif gerak cèlèng mogok. Setelah diulang beberapa kali, kemudian memasuki lagu berikutnya dan penari pun melakukan gerak seblak sampur dan égol ukel buwang kembali. Memasuki puncak klimaksnya, ketika penari melakukan motif gerak ndhaplang saat dinyanyikan lagu Condro Dewi. Dilanjutkan dengan beberapa klimaks kecil, sebelum mencapai ending ketika gending Sampun Saré.

\section{E. Analisis Proses Ritual}

Menurut Victor Turner, dalam sebuah ritual terdapat tahap atau proses ritual yang dialami subjek ritual yakni separasi, liminalitas, dan reagregasi. Tidak hanya sekedar perubahan luar maupun status sosialnya saja yang diamati, melainkan perubahan batin, moral, dan kognitif yang terjadi pada subjek ritual juga tururt diamati. Ritus tidak dipandang sebagai suatu hal yang statis, akan tetapi sebagai suatu proses. (Y.W. Wartaya Winangun, 1990: 68)

\section{Tahap Separasi}

Disebut pula sebagai tahap pemisahan, di mana subjek ritual dipisahkan dari kehidupan masyarakat sehari-hari. Ketika seorang calon telah dipilih untuk mejadi penari Sêblang melalui proses kejiman, berarti ia adalah orang terpilih dari beberapa keturunan penari Sêblang lainnya. Esok harinya ketika beberapa jam sebelum ritual dimulai, salah satu pawang datang berkunjung ke rumah penari Sêblang. Beliau datang menemui kedua orang tua calon penari Sêblang, untuk memohonkan ijin. Selama tujuh hari pelaksanaan ritual subjek tidak diperkenankan menempati rumah yang selama ini ditinggali. Biasanya ia akan tinggal di rumah kerabat dekat, yang letaknya tidak jauh dari rumahnya.

\section{Tahap Liminal}

„Liminalitas" berasal dari kata bahasa latin „limene yang berarti ambang pintu. (Y.W. Wartaya Winangun, 1990: 29) Liminalitas adalah sebuah tahap atau fase, di mana subjek ritual akan mengalami keadaan yang ambigu „tidak disana, dan tidak disinie ${ }^{e}$. Subjek ritual akan mengalami pengalaman yang berbeda jauh dengan kehidupan sehari-harinya, yakni sebuah pengalaman yang ,anti strukture. Pada fase ini subjek ritual berada di tengah-tengah posisi ditandai dengan adanya hukum, kebiasaan, perjanjian dan upacara. (Y.W. Wartaya Winangun, 1990: 32) Ada rasa pasrah dan patuh pada pemimpin dan yang tertinggi menjadi terendah, atau sebaliknya.

Dalam fase liminalitas terbentuk adanya komunitas. (Y.W. Wartaya Winagun, 1990: 47) Istilah komunitas berasal dari kata bahasa Latin ,communitas", yang artinya persekutuan. Sebelum berangkat seorang pawang memberikan wejangan bagi segenap pendukung ritual yang sedang berkumpul, inilah saat-saat di mana apa yang disebut komunitas oleh Turner, terjadi dalam ritual Sêblang. Mereka tidak dikumpulkan pada suatu tempat tertentu, namun tidak melihat siapa yang kaya atau yang miskin, berkumpul atas satu tujuan yang sama. Terlihat pula adanya suatu kepatuhan subjek ritual, akan apa yang diucapkan dan diarahkan oleh pemimpin ritualnya. Penari Sêblang menjadi yang utama, karena dialah yang menjadi mediator antara alam manusia dan leluhurnya menyatukan sebuah hubungan antara mikro dan makro kosmos.

Kehidupan keseharian penari Sêblang, bukan termasuk dalam kategori warga dengan perekonomian yang mapan. Tetetapi keadaannya akan berbeda ketika ia menjadi subjek ritual Sêblang. Banyak orang yang akan berebut meminta doa darinya, untuk segelas air yang dibawanya dari rumah. Banyak orang yang sengaja datang dari jauh, hanya untuk meminta bunga yang tertancap di omproknya dengan berbagai tujuan dan alasan yang mereka yakini. Dalam fase yang ,anti 
strukture ini keadaan akan berbanding terbalik, dengan kenyataan kesehariaan dalam kehidupan sosial.

Dalam fase liminal ini, juga tidak diperkenankan subjek ritual melakukan hubungan seksual meskipun secara hukum maupun agama itu adalah sah. Apabila kita lihat dari fungsinya mengapa ritual ini dilaksanakan, bahwa sebenarnya ritual ini juga termasuk kedalam ritual kesuburan. Wanita yang selalu diibaratkan dengan tanah, yang akan disemai dengan bibit tanaman. Suci secara ritual tidak sekedar dimaknai sebagai seseorang wanita yang menyandang status „perawan", akan tetetapi lebih mengarah pada keadaan lahiriyahnya, yakni dalam keadaan tidak menstruasi, sudah menopause, sedang hamil dan tidak berhubungan badan. Dalam agama Islam pun sudah jelas pengertiannya, ketika seorang pasangan melakukan hubungan intim maka tidak sah ibadahnya, sebelum melakukan mandi junub untuk menyucikan dirinya kembali.

\section{Tahap Transformasi}

Subjek ritual Sêblang juga mengalami tahap transformasi yang berbeda dengan tiga tahapan yang ditetapkan oleh Turner. Tahapan ini digunakan oleh Turner karena upacara ritual yang digunakan sebagai objek materialnya, berlangsung dalam sehari saja. Selain itu ritual yang diteliti oleh Turner, bukanlah upacara di mana Subjek ritualnya mengalami keadaan trance dan masih menjadi dirinya sendiri secara sadar. Subjek ritual Sêblang mengalami fase alih wahana. Wahana berarti kendaraan yang dapat memindahkan dari suatu tempat ke tempat lainnya, diartikan juga sebagai medium yang dipergunakan untuk mengungkapkan, mencapai, atau memamerkan gagasan atau perasaan. (Sapardi Djoko Damono, 2012: 1) Subjek terlebih dahulu mengalami tahapan ini sebab ketika trance ia menyatu serta „memerankan“ sosok yang bukan dirinya.

Dalam satu hari pelaksanaan Sêblang, subjek mengalami tiga fase yang berjalan sekaligus tanpa terputus. Setelah mengalami tahap separasi, kemudian memasuki fase liminalitas dan bertransformasi menjadi sosok baru selama dalam kondisi kesurupan. Meskipun usai ritual penari telah sadarkan diri kembali menjadi dirinya, bukan berarti ini dianggap tahap reagregasi. Subjek hanya sekedar kembali menjadi dirinya sendiri, belum kembali pada kehidupan sosialnya. Ketiga proses ini berputar dan berjalan terus menerus tanpa terputus selama tujuh hari. Ritual Sêblang akan dianggap sah apabila dilakukan dalam tujuh hari, jika gagal trance maka prosesinya akan diulangi kembali.

Apabila dilihat lagi dari beberapa aspek yang dalam ritual ini, selain sebagai sebuah ritus tolak bala sebenarnya ritual Sêblang Olehsari termasuk kedalam jenis ritus kesuburan. Sajén kinangan, Omprok yang terbuat dari bunga segar dengan sebuah kaca kecil di bagian atasnya, Kembang dirma yang terdiri dari bunga kanthil berwarna putih, dan juga sesaji êmpon-êmpon yang di gantung di Para Bungkil, serta menu masakan utama yang wajib dalam ritual Sêblang adalah pêcêl pitik. Semua hal itu adalah sesaji dan makanan yang digemari oleh Dewi Sri. (Purwadi, 2004: 142)

Interpretasi ini juga diperkuat dengan keterangan narasumber, bahwa syair dalam lagu Condro Dewi ditujukan untuk Dewi Sri. (Wawancara dengan bapak Ikhwan, 2015) Kata Condro dalam bahasa Sansekerta yang artinya rembulan, sebagai salah satu benda langit dan dimaksudkan seorang dewi yang turun dari kahyangan sedangkan kata murtosiyo yang artinya turunlah atau hadirlah. Diduga kuat bahwa Condro Dewi sebenarnya merupakan penyebutan lain masyarakat Olehsari terhadap Dewi Sri, sebagai ,,sosok ${ }^{e e}$ yang sedang diperankan oleh penari Sêblang.

\section{Tahap Reagregasi}

Fase di mana subjek ritual dipersatukan kembali dengan masyarakat dan kehidupan sosialnya sehari-hari. Setelah melalui masa liminalitasnya, inilah saatnya hasil refleksi formatifnya itu diterapkan. Dalam ritual Sêblang fase ini ditandai dengan prosesi 
Ngêlungsur, yang dilaksanakan dihari ke delapan setelah serangkaian ritual Sêblang usai dilaksanakan. Secara sah penari Sêblang dan para pendukung ritual telah usai melakukan tugas dan tanggung jawabnya.

Apabila digambarkan dalam skema, proses ritual yang terjadi pada subjek ritual Sêblang Olehsari seperti berikut:

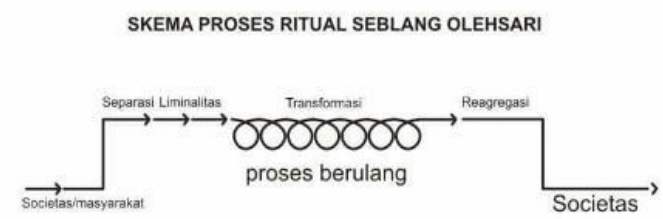

Dalam teori proses ritual Turner, fase proses ritual yang dialami subjek digambak dengan skma yang berjalan linier dan tidak terdapat tahap transformasi.

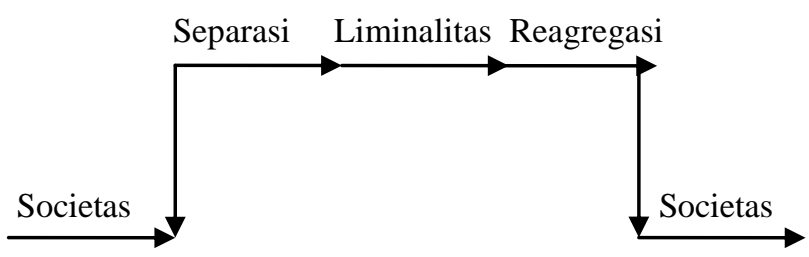

\section{F. FenomenaTrance dalam ritual Sêblang Olehsari}

Trance is a pscychological state induced by (or as if induced by) a magical Incantation, a ritual recitation of words or sounds believed to have a magical effect. (Bettina Schmidt and Lucy Huskinson, 2010: 3) Artinya trance merupakan kondisi psikologis subjek, yang dipengaruhi dengan kata maupun suara yang memiliki efek magis. Kesurupan terjadi karena individu memiliki berbagai afeksi atau perasaan yang ingin diungkapkan, namun tidak tercapai karena kondisi lingkungan. Possession Syndrome merupakan keadaan kesurupan yang terjadi pada manusia namun tidak untuk kebutuhan suatu ritual, sedangkan trance dimaknai sebagai fenomena kesurupan yang terjadi dalam ritual. (Wawancara narasumber: Tirza, 2015)
Women are more religious than Man, but why?". Pendapat ini diungkapkan dalam pembahasan tentang ritual di Afrika, yang subjek ritualnya adalah seorang wanita. Sepanjang sejarah dilaporkan bahwa lembaga keagamaan yang merekrut perempuan jauh lebih berhasil daripada dengan pria. Setidaknya mereka para wanita bukanlah kategori terkecualikan dalam suatu organisasi. Bahkan ketika para laki-laki mendominasi pada posisi pimpinan, para wanita mendominasi dalam jumlah anggotanya. Sehingga wanita secara umum digambarkan „lebih religius dibandingkan"e para pria. (Bettina Schmidt and Lucy Huskinson, 2010: 93) Disisi lain, wanita dianggap lemah dan rentan, sehingga mudah untuk dipengaruhi dan membuat, ,spirite tersebut memuja kecantikan mereka, selain itu wanita juga telah dilatih untuk menjadi lebih religius sejak kecil.

\section{G. Kesimpulan}

Tradisi ritual Sêblang Olehsari tidak dapat dipisahkan dengan peranan penari wanita muda sebagai mediator, yang menari dalam keadaan kesurupan atau trance. Subjek harus dalam keadaan suci secara ritual, namun tidak sekedar dimaknai sebagai seseorang wanita yang menyandang status ,perawan ${ }^{\text {ee }}$. Hal ini lebih mengarah pada keadaan lahiriyahnya, yakni dalam keadaan tidak menstruasi, sudah menopause, tidak sedang hamil dan tidak berhubungan badan. Pada ritual Sêblang, status perawan dimaksudkan pada keadaan wanita tersebut ketika menjadi penari Sêblang untuk pertama kalinya. Bentuk dan struktur teks tari dalam ritual Sêblang dilakukan keadaan trance dengan memiliki motif gerak sapon, ndhaplang, égol dan cèlèng mogok.

Berdasarkan hasil analisis teks dari tari dalam penelitian ini ditemukan terdapat motif gerak egol ukel buwang yang mengandung unsur gerak égol di dalamnya. Berdasarkan hasil analisis proses ritual yang dialami subjek ritual, disimpulkan bahwa subjek mengalami empat tahapan yakni separasi, liminalitas, transformasi, dan reagregasi. Pada tahap 
transformasi subjek mengalami proses alih wahana atau berubah menjadi ,peran yang lain ${ }^{e e}$. Ritual yang diteliti oleh Turner bukanlah suatu upacara di mana subjek ritualnya mengalami keadaan trance artinya subjek tetap sebagai dirinya sendiri secara sadar, sehingga tahap transformasi tidak ditemukan dalam proses ritual Turner. Skema ritual Sêblang digambarkan berbentuk spiral karena proses ritual separasi, liminalitas, dan transformasi terjadi berulang-ulang dan berjalan terus menerus tanpa terputus selama tujuh hari.

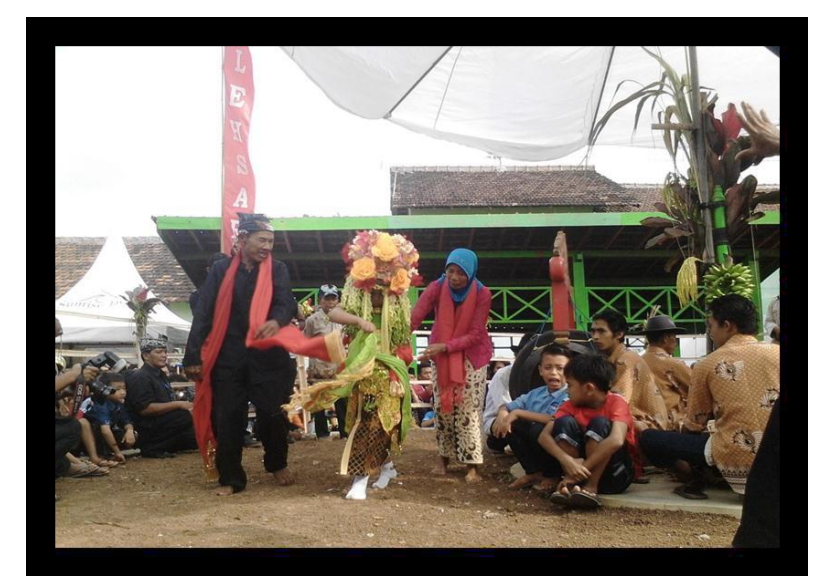

Penari bersama Pêngudang dan Pendamping (Dok. Aulia Renata, 2015)

\section{DAFTAR SUMBER ACUAN}

\section{A. Sumber Tercetak}

Ali, Hasan. 1993. Bahasa dan Sastra Osing di Banyuwangi. Surakarta: Penerbit Harapan Massa.

Arps, Bernard (ed). 1993. Performance in Java and Bali. London: School of Oriental and African Studies University London.

Budi Setianto, Eko. TT. Bunga Rampai Ritual Adat dan Tradisi Masyarakat Banyuwangi. Banyuwangi: Dinas Kebudayaan dan Pariwisata Kabupaten Banyuwangi.

Dariharto. 2009. Kesenian Gandrung Banyuwangi. Banyuwangi: Dinas
Kebudayaan dan Pariwisata Kabupaten Banyuwangi.

Damono, Sapardi Djoko. 2012. Alih Wahana. Penerbit: Editum.

E Schmidt, Bettina dan Lucy Huskinson. 2010. Spirit Possession and Trance New Interdisciplinary Perspective. New York: MPG books group.

Habsari, Lintang. 2012. "Etnografi Tari Sêblang pada Upacara Bersih Desa". Skripsi S-1 Program Studi Antropologi Tari, Fak. Seni Pertunjukan, IKJ.

Koentjaraningrat, Prof. Dr. 2007. Sejarah Teori Antropologi. Jakarta: UI-Press.

2010. Manusia dan Kebudayaan di Indonesia. Jakarta: Djambatan.

Laksono, Kisyani. 2004. Bahasa Jawa di Jawa Timur Bagian Utara dan Blambangan. Jakarta: Pusat Bahasa.

Martono, Hendro. 2012. Panggung Pertunjukan dan Berkesenian. Yogyakarta: Cipta Media.

Murgiyanto, Sal dan A.M. Munardi. TT. Sêblang dan Gandrung Dua Bentuk Tari Tradisi di Banyuwangi. Penerbit: Proyek Pembinaan Media Kebudayaan Jakarta.

Purwadi. 2004. Asal-Usul Sejarah Nenek Moyang Orang Jawa. Yogyakarta: Tunas Harapan.

Pudjasworo, Bambang. 2011. "Tari Kebyar dalam Perkembangan Politik, Sosial, Ekonomi dan Budaya di Bali abad XX". Disertasi Program Studi Pengkajian Seni Pertunjukan dan Seni Rupa, Universitas Gadjah Mada.

Pramutomo, R.M. (ed.) .2007. Etnokoreologi Nusantara. Surakarta: ISI Press, Institut Seni Indonesia Surakarta. 
Saputra, Heru SP. 2007. Memuja Mantra Sabuk Mangir dan Jaran Goyang. Yogyakarta: LKIS.

Singodimajan, Hasnan. 2009. Ritual Adat Sêblang Sebuah Seni Perdamaian Masyarakat Osing Banyuwangi. Banyuwangi: Dinas Kebudayaan dan Pariwisata Kabupaten Banyuwangi.

Sumaryono, 2011. Antropologi Tari dalam Perspektif Indonesia. Yogyakarta: BP ISI Yogyakarta.

Soedarsono. 1978. Diktat Notasi Laban. Jakarta: Dirjen Pembinaan Kesenian dan Kebudayaan, Departemen P dan K.

Y. Sumandiyo Hadi. 2007. Kajian Tari Teks dan Konteks. Yogyakarta: Pustaka

Widaryanto, FX. 2007. Antropologi Tari. Bandung: Sunan Ambu Press STSI Bandung.

WS, Tri Broto, dkk. 2009. Koreografi Etnik Tari Jawa Timur. Penerbit: Dewan Kesenian Jawa Timur.

\section{B. Diskografi}

Video dokumentasi pelaksanaan ritual Sêblang Olehsari pada tanggal 8-8-2014, koleksi pribadi Vicky Hendri Kurniawan.

Video dokumentasi pelaksanaan Sêblang Olehsari tahun 2013, koleksi Dinas Kebudayaan dan Pariwisata Banyuwangi.

Video dokumentasi pelaksanaan ritual Sêblang Bakungan tahun 2014, koleksi pribadi Vicky Hendri Kurniawan.

\section{E-Journal}

Heru SP Saputra. 2014. Respon Orang Osing
Terhadap Sakralitas dan Fungsi Sosial Ritual Sêblang.

Journal.ui.ac.id/index.php/humanities/article/vi ewFile/3461/2741. Diunduh pada tanggal 09-02-2015.

Novi Anoegrajekti. 2003. Sêblang Using: Studi Tentang Ritus dan Identitas Komunitas Using. Sastra.um.ac.id. Diunduh pada tanggal 11-02-2015.

Heru Subagyo. 2003. Bentuk dan Makna Simbolik Tari Sêblang di Desa Olehsari Kabupaten Banyuwangi Jawa Timur. Jurnal.isi-ska.ac.id. Diunduh pada tanggal 12-04-2015.

\section{Webtografi}

www.BalaiBahasaSurabaya.com Diunduh pada tanggal 5-6-2015.

Wikipedia.org/wiki/Glagah_Banyuwangi.

Diakses pada tanggal 22/4/15 pukul 13.06 WIB.

filosofiJawa-teropong-news.com, diakses pada tanggal 19-06-2015.

Alkitab.sabda.org, diakses pada tanggal 19-62015.

Kbbi.web.id/transformasi, di akses tanggal 23-06-2015 pukul 22.08 WIB.

icl.googleusercontent.com/?lite_url=http://id.m .wikipedia.org/wiki/represi_psikologis\&ei=LP M-nwL7\&Ic=id-ID\&s=1. Diunduh pada tanggal 24-05-2015.

masnur.mwb.im/pengertian-musik-trance-apaitu-genre-mu-2.xhtml. Diakses pada tanggal 25/5/2015.

banyuwangikab.go.id. Diakses pada tanggal 12-7-2015. 


\section{E. Narasumber}

1. Nama: Sueidah

Umur: 20 tahun

Penari Sêblang Olehsari

2. Nama: Sri Handayani

Umur: 47-50 tahun

Warga desa Olehsari, pelaku dan pengamat ritual Sêblang

\section{Nama: Arif Wibowo}

Umur: 23 tahun

Warga desa Olehsari dan pengamat ritual Sêblang.

\section{Nama: Heru SP Saputra}

Umur: 50 tahun

Dosen Universitas Negeri Jember, warga desa Olehsari dan peneliti ritual Sêblang.

5. Nama: Busyairi

Umur: 62 tahun

Ketua adat Sêblang Bakungan

6. Nama: Asmah

Umur: 70 tahun

Mantan penari Sêblang Olehsari

7. Nama: Mbah Nik

Umur: 70 tahun

Sesepuh desa Olehsari, sering mengalami kejiman untuk menentukan memilih penari Sêblang Olehsari.

8. Nama: Mbah Juni (alm.)

Umur: 80 tahun

Mantan penari Sêblang Olehsari.

9. Nama: Bapak Suko

Umur: 75 tahun

Pawang Sêblang Olehsari.

10. Nama: Bapak Wawan

Umur: 37 tahun

Seniman Banyuwangi dan dosen karawitan STK Wilwatikta Surabaya.
11. Nama: Bapak Ikhwan

Umur: 40 tahun

Seniman daerah Rogojampi, pemain musik, serta pengamat kesenian Banyuwangi. 